\title{
A rare case of obstructed hemivagina and ipsilateral renal agenesis syndrome presented with haematocolpos and haematometra
}

\author{
Auxeelia Packia Devi R.*, Valsa Diana, Geetha M. Kumar
}

Department of Obstetrics and Gynecology, RGGWCH, Pondicherry, India

Received: 10 January 2022

Accepted: 05 February 2022

*Correspondence:

Dr. Auxeelia Packia Devi R.,

E-mail: auxeellia@yahoo.co.in

Copyright: (c) the author(s), publisher and licensee Medip Academy. This is an open-access article distributed under the terms of the Creative Commons Attribution Non-Commercial License, which permits unrestricted non-commercial use, distribution, and reproduction in any medium, provided the original work is properly cited.

\begin{abstract}
Obstructed hemivagina and ipsilateral renal anomaly (OHVIRA) syndrome is a syndrome characterised by obstructed hemivagina, ipsilateral renal agenesis and uterine didelphys. It is a rare congenital anomaly results from defective fusion of the Müllerian ducts during development of the female reproductive system. It is also known as Herlyn-WernerWunderlich syndrome. Aim of the study was to project a rare case of developmental anomaly of Mullerian system. OHVIRA syndrome is rare anomaly. The most common presentation of this syndrome is a mass secondary to hematocolpos, pain, and dysmenorrhea. Incidence rate is $0.1-3 \%$. Other symptoms are swelling of the abdomen, nausea and vomiting due to pelvic pain, and fertility may also be affected. Diagnosed by magnetic resonance imaging (MRI) and ultrasound. This case was managed by diagnostic laparoscopy with resection of vertical vaginal septum. Other treatment option is vaginoscopic incision of the oblique vaginal septum. High level of clinical suspicion and early surgical intervention will prevent further complications.
\end{abstract}

Keywords: OHVIRA syndrome, Vertical vaginal septum

\section{INTRODUCTION}

Vertical vaginal septum is a rare cause of genital outflow tract obstruction. It results from incomplete fusion between the vaginal components of the Mullerian ducts and the urogenital sinus. By the end of $20^{\text {th }}$ century, embryology of female urogenital system was accepted to be a truly settled issue. The embryologic origin of vagina develops from fusion of Mullerian ducts proximally and urogenital sinus distally. Fusion of sinovaginal bulbs to uterovaginal primordium forms the vaginal plate and it becomes canalized to form the patent vagina. Incomplete canalization of the vaginal plate leads to defects of vertical fusion such as vertical vaginal septum. Aberration in vertical or lateral fusion or arrest of paramesonephric ducts during the course of development explains various uterine anomalies. Unilateral renal agenesis occurs when one or both ureteral buds fail to form and the metanephric blastema does not differentiate in to nephrons. The syndrome of obstructed hemivagina and ipsilateral renal anomaly (OHVIRA) was first reported in 1922 and is also known as Herlyn-Werner- Wunderlich syndrome. ${ }^{1}$ A new classification system for Herlyn-Werner-Wunderlich syndrome was created in $2015 .^{2}$ In OHVIRA syndrome, the developmental arrest of paramesonephric duct results in development of uterine didelphys, failure of fusion of ipsilateral paramesonephric ducts with sinovaginal bulb results in failure of distal vagina to develop, thereby causing obstructed hemivagina and renal anomalies. A very few cases have been reported in literature. Here we report a case of OHVIRA syndrome.

\section{CASE REPORT}

An 18 year old unmarried girl presented to outpatient department (OPD) with complaints of lower abdominal pain since one year. She attained menarche at 14 years of age with regular cycles, moderate flow and was associated with dysmenorrhea. On examination, abdomen was soft and uterus enlarged to 12 weeks size. On local 
examination, there was a bulge seen in the vagina on the right side probably due to vaginal septum. Transabdominal ultrasound (USG) showed oval shaped fluid filled structure seen posterior to bladder measuring $6.3 \times 6.6 \mathrm{~cm}$ with small constriction in the oval portion suggestive of haematometra and haematocolpos. Multicystic right adnexal lesion was seen measuring $7.7 \times 2.9 \mathrm{~cm}$ suggestive of right haematosalpinx. Both ovaries were separately visualized and were normal. Bilateral cornua appeared prominent. Right cornua showed a fluid collection. Left cornua separately visualized. Right kidney was not visualized (Figure 1).

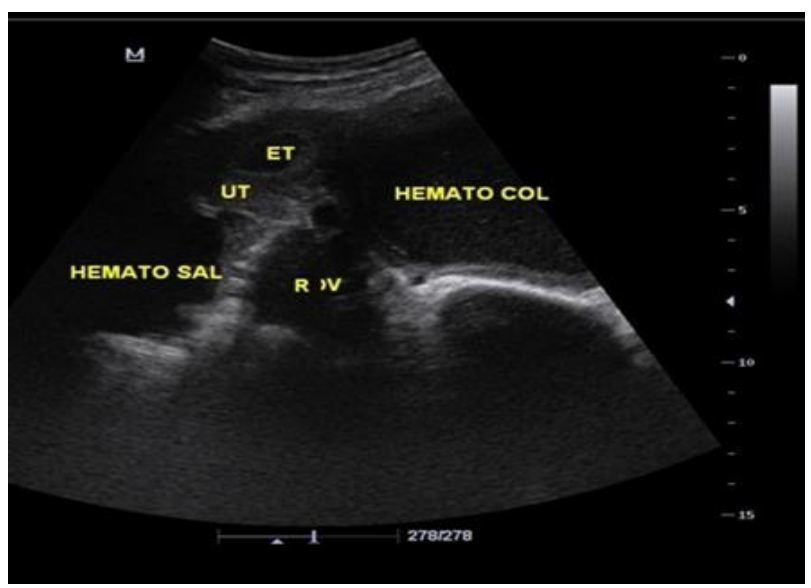

Figure 1: Ultrasonographic picture of hematocolpos and hematosalpinx.

Further evaluation with MRI was done. MRI showed right renal agenesis with hematometra and hematosalpinx due to vertical vaginal septum. A diagnosis of OHVIRA syndrome was made.

Examination under anaesthesia, revealed right anterolateral cystic swelling in upper $2 / 3^{\text {rd }}$ of vagina. A small cervix felt on left side of at $1^{\circ}$ clock position in vagina.

On laparoscopic visualization, uterus was enlarged up to 12 weeks size with omental adhesions. A cruciate incision was made on the dependent part of the septal bulge and around $500 \mathrm{ml}$ of altered menstrual blood was drained. On Laparoscopy, after drainage of menstrual blood, uterine didelphys with right haematosalpinx was clearly visualized (Figure 2). Right ovary appeared normal. Left fallopian tube and ovary were normal. Diagnostic laparoscopy with resection of vertical vaginal septum was done. Excision of redundant vaginal septum was done revealing another cervix on the right side. Vaginal moulding kept with 20 F Foley's catheter. Patient was relieved from her symptoms. Post-operative follow up ultrasound after two months revealed complete disappearance of hematocolpos and normal vagina was visualized. The surgical outcome was satisfactory with expectation of near normal fertility and sexual abilities.

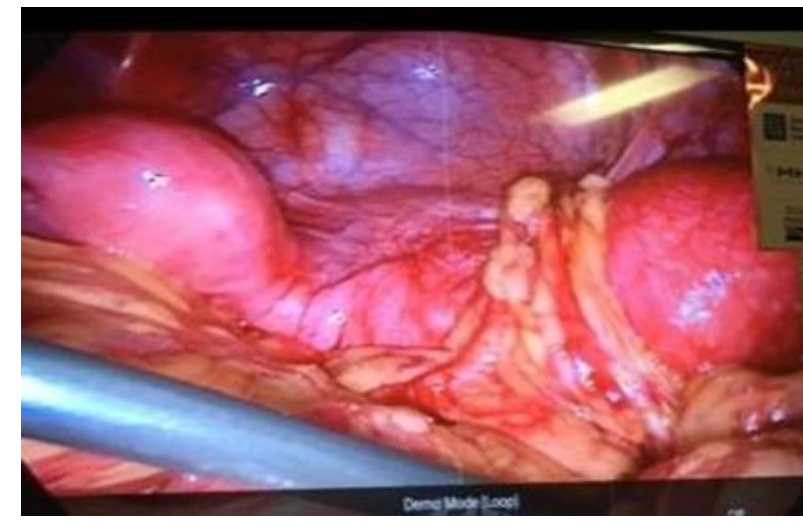

Figure 2: Laparoscopic view of uterine didelphys after drainage.

\section{DISCUSSION}

Although the true incidence of Mullerian defect is 1.1 to $3.5 \%$, it is believed to be much higher (around 25\%) in women with recurrent miscarriages and sub fertility. ${ }^{3}$ Review of literature in 15 reported studies constituting 1771 patients during 1965-1996 period revealed mean incidence of uterine didelphys to be $11.1 \%$. HerlynWerner-Wunderlich syndrome is a rare syndrome usually diagnosed after the menarche when the patients present with lower abdominal pain and occasional palpable mass in the pelvis. MRI is the investigation of choice for such anomalies. ${ }^{4} \mathrm{~A}$ high index of suspicion is required for diagnosing the cases with Mullerian anomalies. This condition can be treated by excision of vaginal septum and delay in diagnosis may worsen the associated endometriosis. Laparoscopy remains the gold standard for diagnosis with additional therapeutic drainage of haematocolpos, vaginal septostomy and marsupialisation. An early and correct diagnosis is the goal to relieve the symptoms and also preserve sexual and conception abilities. Two stage vaginoplasty in the form of drainage of the hematocolpos in one operation followed by another operation to resect the septum is the classic treatment option. Women with uterus didelphys have a high pregnancy rate of $80 \%$ (Heinonen, 2000) but with elevated rates of premature delivery (22\%) and abortion (74\%); cesarean section is necessary in over $80 \%$ of patients because breech position has a higher incidence. ${ }^{6}$ In addition to relief of pain due to obstruction, surgery also reduces chances of pelvic endometriosis due to retrograde menstrual seeding. Patients are able to have normal sexual life. ${ }^{7}$

\section{CONCLUSION}

A young girl with OHVIRA syndrome was diagnosed with high level of clinical suspicion, radiological and diagnostic laparoscopic assistance. Early surgical intervention will prevent further complications and provide the patient to lead normal sexual life and be able to conceive and carry pregnancy to term. OHVIRA syndrome is an uncommon 
congenital anomaly with clinical significance and simple surgical management.

\section{ACKNOWLEDGMENTS}

Authors would like to express their sincere thanks to Dr. P. Sujatha DGO, DNB (obstetrics and gynaecology), MNAMS, Medical superintendent, Rajiv Gandhi Government Women and Children Hospital, Dr. Raguveer M.S. E.N.T., Mch plastic surgery, chief medical officer, department of plastic surgery, Indira Gandhi Government General Hospital, and Dr. Ravichandran DMRD, head of the department, radiology, Indira Gandhi Government General Hospital, Pondicherry for their enormous support in doing this study.

Funding: No funding sources Conflict of interest: None declared

Ethical approval: Not required

\section{REFERENCES}

1. Singh K, Chakur S, Sonya A, Verma A. Herlyn Werner Wunderlich Syndrome: A rare Urogenital Anomaly with Unusual presentation in two cases with Review of Literature. Clinics mother child health. 2016;13:222.

2. Rezai S, Ligorski C, HughesA, Fuller PN, Henderson CE. Three Cases of Didelphys Uterus, Including Uterus Didelphys with Obstructed Hemivagina and
Ipsilateral Renal Agenesis (OHVIRA Syndrome AKA Herlyn-Werner- Wunderlich Syndrome), with a Systematic Review. Obstet Gynecol Int J. 2017;7(2):00241.

3. Rudra S, Dahiya N. OHVIRA syndrome: A rare variant of mullerian duct anomaly. Int $\mathbf{J}$ Reprod Contracept Obstet Gynecol. 2017:6(1):326-8.

4. Tug N, Sagin MA. Treatment of Virgin OHVIRA syndrome with Heamatometrocolpos by complete Incision of vaginal septum without hymenotomy. J Clin Diag Res. 2015;9:11.

5. Youssef AFM. Obstructed hemivagina and ipsilateral renal anomaly syndrome with uterus didelphys (OHVIRA). Middle East Fertil Soc J. 2013;18(1):5861.

6. Sleiman Z, Zreik T, Bitar R, Sheaib R, Bederi AA, Tanos V. Uncommon presentations of an uncommon entity: OHVIRA syndrome with hematosalpinx and pyocolpos. Facts Views Vis Obgyn. 2017;9(3):16770.

7. Bajaj SK, Misra R, Thukral BB, Gupta R. OHVIRA: Uterus didelphys, blind hemivagina and ipsilateral renal agenesis: Advantage MRI. J Hum Reprod Sci. 2012;5(1):67-70.

Cite this article as: Auxeelia Packia Devi RAP, Diana V, Kumar GM. A rare case of obstructed hemivagina and ipsilateral renal agenesis syndrome presented with haematocolpos and haematometra. Int J Reprod Contracept Obstet Gynecol 2022;11:962-4. 